\title{
Developing a Pedagogical Framework and Design Principles for a STEM Learning Environment Design
}

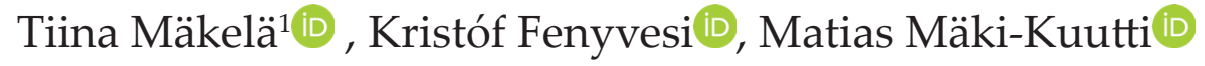 \\ University of Jyväskylä, Finland
}

\begin{abstract}
The need for effective and attractive learning environments (LEs) for science, technology, engineering, and mathematics (STEM) has been internationally recognized. Additionally, the connection between STEM learning and cross-curricular skills such as creativity, innovation, and entrepreneurship has garnered attention. A deep theoretical and empirical understanding is required when designing STEM LEs. In this study, a pedagogical framework for STEM LEs has been developed based on feedback from students, aged 10-18 years old, teachers, school directors, parents, and STEM professionals, and supported by the literature. First, representatives of key stakeholder groups in Belarus, Finland, Germany, Greece, and Spain (total n =132) were invited to co-design focus group (FG) 1 sessions to collect their wishes related to STEM LEs. The data was collected through an online survey with open-ended questions. The analysis of the data led to the design of the pedagogical framework, which was validated by the same stakeholder groups (total $n=137$ ) in FG2 discussions. The empirically and theoretically grounded framework entails general design principles as well as principles related to ways of teaching and learning, socio-emotional aspects, and cross-curricular skills. Both the results of this study and the previous literature suggest that different pedagogical design principles are highly interrelated. For instance, novel tools and methods, collaborative methods, reflective learning, and entrepreneurial skills may support creativity and innovation, and vice versa. Therefore, instead of focusing on singular design principles, we recommend considering a wide range of different LE design principles to support multiple ways of teaching and learning, and to develop both subject-related and cross-curricular knowledge, skills, attitudes, values, and ethics.
\end{abstract}

Keywords: STEM, learning environment, pedagogical framework, pedagogical design principles, focus group, co-design

\section{Introduction}

The need for effective and attractive learning environments (LEs) for teaching and learning science, technology, engineering, and mathematics (STEM) has been recognized on both the European and global levels (see, e.g., European Union, 2016). Additionally, STEM learning is expected to be connected with cross-curricular skills related to creativity, innovation, entrepreneurship, and professional skills as well as with environmental, social, cultural, and economic sustainability (Edwards-Schachter et al., 2015; European Commission, 2018; Frisk \& Larson, 2011).

It is generally acknowledged that it is vital to base LE designs on a deep educational understanding that is both theoretical and empirical. Previous studies have suggested that it is important to integrate the perspectives of students, teachers, and designers in participatory LE designs (Könings et al., 2014). In addition to students and teachers, inviting parents or external experts to the design process is useful for improving the connections between home, school, and the wider community (see Mäkelä \& Helfenstein, 2016). The challenge, however, is developing pedagogical frameworks that entail design principles (i.e., principles guiding the design of LEs) that

${ }^{1}$ Corresponding Author: Finnish Institute for Educational Research, University of Jyväskylä, Finland. Email: tiina.m.makela@jyu.fi

Mäkelä, T., Fenyvesi, K., \& Mäki-Kuutti, M. (2020). Developing a pedagogical framework and design principles for a STEM learning environment design. Journal of Research in STEM Education, 6(1), 1-17. 
integrate both theory and various stakeholders' views in a balanced manner (see Jiménez Iglesias et al., 2016).

This paper presents a study in which primary, lower secondary, and upper secondary school students, teachers, school directors, parents, and STEM professionals in Belarus, Finland, Germany, Greece, and Spain were involved in the participatory co-design of a hybrid (virtual, physical, formal, and informal) STEM LE. The first aim of this paper is to present the validated results regarding the participants' wishes on teaching, learning, assessment, and motivation both in general and in relation to STEM subjects and cross-curricular skills (see the Results section). The second aim is to integrate the participants' wishes with the research literature to create a theoretically and empirically grounded pedagogical framework and design principles to support STEM LE designs in particular and LE designs in general (see the Discussion section).

This study is part of a broader European research project named Science, Technology, Innovation, Mathematics, Education for the Young (STIMEY), funded by the European Union's Horizon 2020 research and innovation program (2016-2019). The project researches and develops a hybrid educational environment with the aim of making STEM education more attractive to young people aged 10 to 18 years old. The STIMEY LE consists of components such as a social web platform, e-portfolio, robots, serious games, entrepreneurial tools, and a digital radio. It connects various stakeholders in shared efforts to engage and increase both female and male students' interest and motivation in STEM education, innovations, and careers from a young age.

In addition to STEM subjects, the STIMEY project focuses on cross-curricular skills (also referred to in the literature as transversal skills or competencies, twenty-first century skills, or key competences with different overtones in different contexts) particularly related to creativity and innovation, entrepreneurship, and professional life, as well as skills related to sustainability. For instance, a model for entrepreneurial tournaments was developed to engage learners in innovative processes and to stimulate their creative thinking. In the context of presenting the STIMEY pedagogical framework and design principles, we decided to use the term "cross-curricular skills" to underline the integrative, holistic (i.e. "cross-curricular") nature of the underlying theoretical and pedagogical efforts, and the active and learnable character of the fostered competencies (i.e., "skills"). As Amadio (2013, p. 7) pointed out, none of the skills included in cross-curricular configurations are especially new. However, what makes their role central in the current policy discussions is "the increased attention paid to the application of knowledge and skills to 'real life situations' as well as to the labor market demands arising from the changes in society due to the globalized economy and the information age." The cross-curricular design principles, in particular, play an important role in ensuring that the STIMEY LE does not only follow, but in many respects, proactively enhances the application of knowledge and skills (Wright \& Davis, 2014). Furthermore, by offering several digital tools and opportunities for participation, networking, and play (Jenkins, 2006), the crosscurricular design principles are intended to facilitate the transition from the traditional "teacherbased approach" toward an active "learning-based approach" (Thomas \& Brown, 2011).

In the first phase of the pedagogical framework development, participating Finnish and Greek stakeholders' wishes in relation to teaching and learning in general, and STEM subjects in particular were analyzed, and the results were discussed in light of the literature (Mäkelä et al., 2017). The present analysis was then extended to participants in Belarus, Germany, and Spain during two rounds of stakeholder involvement in all participant countries. In addition to stakeholders' wishes in relation to teaching and learning in general, and STEM subjects in particular, stakeholders' responses regarding cross-curricular skills were also analyzed, and the analysis was supported by a more extensive body of literature.

\section{Method}

Stakeholders were involved in the development of the pedagogical framework from the beginning. Thus, not only previous studies and theories, but also relevant aspects for the key stakeholders were included. A participatory design approach (Könings et al., 2014; Mäkelä \& 
Helfenstein, 2016) and focus group techniques (Duarte et al., 2015) were combined in the focus group (FG) co-design sessions (see also Mäkelä et al., 2017) with various stakeholders.

Key stakeholder groups' wishes were first collected in FG1 co-design sessions in all participant countries. Framework and design principles were constructed based on an analysis of the participants' wishes. Then, in FG2 sessions, the framework and design principles were presented to the stakeholder groups as a form of member check or member validation (see Koelsch, 2013). The aim was to receive feedback from the participants and assure the truthfulness of our data interpretations as well as pragmatic validity or usefulness for the construction of the pedagogical framework. This allowed the participants to provide critical evaluations of the findings and to either confirm their accuracy and completeness or add aspects that they considered relevant. After this, theoretical and empirical literature was used to support the selection of the design principles for the framework. In this article, the support literature is presented in the Discussion section.

\section{Participants}

The participants representing the main stakeholder groups relevant to this project included primary, lower secondary, and upper secondary school students, aged 10-18 years, school directors, teachers, parents, and professionals working in STEM careers, all of whom were invited to FG sessions. It was ensured that the participant sample was gender balanced.

\section{FG1 Sessions}

Table 1 displays the number of participants in FG1 sessions for each stakeholder group by country and as a whole. Of the participants, $55 \%$ were female and $45 \%$ were male.

Table 1.

Stakeholder Groups per Each Country in FG1 Sessions

\begin{tabular}{lcccccc}
\hline Stakeholder groups/countries & $\begin{array}{c}\text { Finland } \\
\mathbf{n}=\end{array}$ & $\begin{array}{c}\text { Germany } \\
\mathbf{n}=\end{array}$ & $\begin{array}{c}\text { Belarus } \\
\mathbf{n}=\end{array}$ & $\begin{array}{c}\text { Greece } \\
\mathbf{n}=\end{array}$ & $\begin{array}{c}\text { Spain } \\
\mathbf{n}=\end{array}$ & $\begin{array}{c}\text { Total } \\
\mathbf{n}=\end{array}$ \\
\hline Primary school students & 4 & 11 & 2 & 2 & 4 & 23 \\
Lower secondary school students & 6 & 2 & 6 & 2 & 5 & 21 \\
Upper secondary school students & 2 & 7 & 2 & 2 & 4 & 17 \\
Teachers & 3 & 2 & 3 & 6 & 2 & 16 \\
Directors & 3 & 3 & 3 & 3 & 2 & 14 \\
Parents & 5 & 3 & 4 & 6 & 4 & 22 \\
STEM professionals & 2 & 0 & 2 & 3 & 1 & 8 \\
(business and research) & 2 & 2 & 5 & 0 & 2 & 11 \\
University students & 27 & 30 & 27 & 24 & 24 & 132 \\
\hline Total $\mathbf{n}=$ & & & & &
\end{tabular}

FG2 Sessions

The aim was to include the same participants in FG2 that were in FG1, but also to invite new participants who would evaluate the results without prior participation in the project. Of the participants, $49 \%$ were female and 51\% were male. Table 2 displays the participants in FG2, representing different stakeholder groups. As can be seen, $49 \%$ of the participants had also participated in FG1 sessions. 
Table 2.

Stakeholder Groups per Each Country in FG2 Sessions

\begin{tabular}{lcccccc}
\hline Stakeholder groups/countries & $\begin{array}{c}\text { Finland } \\
\mathbf{n}=\end{array}$ & $\begin{array}{c}\text { Germany } \\
\mathbf{n}=\end{array}$ & $\begin{array}{c}\text { Belarus } \\
\mathbf{n}=\end{array}$ & $\begin{array}{c}\text { Greece } \\
\mathbf{n}=\end{array}$ & $\begin{array}{c}\text { Spain } \\
\mathbf{n}=\end{array}$ & $\begin{array}{c}\text { Total } \\
\mathbf{n}=\end{array}$ \\
\hline Primary school students & 7 & 12 & 1 & 2 & 4 & 26 \\
Lower secondary school students & 7 & 6 & 7 & 2 & 5 & 27 \\
Upper secondary school students & 2 & 10 & 2 & 3 & 4 & 21 \\
Teachers & 3 & 2 & 4 & 6 & 2 & 17 \\
Directors & 2 & 0 & 3 & 4 & 1 & 10 \\
Parents & 3 & 1 & 3 & 6 & 2 & 15 \\
STEM professionals (business and & 2 & 4 & 2 & 2 & 1 & 11 \\
research) & 1 & 2 & 5 & 0 & 2 & 10 \\
University students & 27 & 37 & 27 & 25 & 21 & 137 \\
\hline Total $\mathbf{n}=$ & 12 & 8 & 12 & 15 & 20 & 67 \\
\hline N (\%) of participants from the FG1 & $(44 \%)$ & $(22 \%)$ & $(44 \%)$ & $(60 \%)$ & $(95 \%)$ & $(49 \%)$ \\
\hline
\end{tabular}

\section{Materials}

\section{FG1 Sessions}

Materials for FG1 sessions involving various stakeholders in the STIMEY LE design were developed in collaboration with the research partners participating in the STIMEY project, first in English and then translated into local languages. FG discussions collected participants' wishes related to the main topics covered in the STIMEY project: teaching and learning, STEM subjects, cross-curricular skills, social media, games and gamification, digital platform, radio, social robots, gender, and safety issues. These topics were presented to the participants on slides displaying inspirational images of each topic. Participants' wishes related to each topic were collected using an online survey with open-ended questions.

Materials were designed based on the grounded theory approach (Strauss \& Corbin, 1998). Instead of referring to specific theories on learning and motivation and pre-defining these concepts for the participants, we were interested in their ideas related to these topics. This document concentrates on an analysis of the participants' responses to the following main topics and their subsections relevant for the framework development: wishes on (1) teaching and learning (1.1. teaching, 1.2. learning, 1.3. assessment, and 1.4. motivation); and (2) STEM subjects (2.1. teaching, 2.2. learning, and 2.3. motivation). In addition, wishes on specific (3) cross-curricular skills (3.1. creativity, 3.2. sustainability skills, 3.3. entrepreneurship, and 3.4. connectedness with professional life) were included in the analysis. These topics and skills were considered most relevant for the STIMEY project's objectives.

\section{FG2 Sessions}

Materials for FG2 sessions entailed a presentation of the pedagogical framework and design principles, which were created based on the data collected in FG1 sessions. Further, results related to wishes regarding different STIMEY LE components (e.g., platform, radio, and robots) were presented. In addition to the oral conversations and feedback received during the sessions, a gamified Kahoot survey tool was used for member check/validation. This tool displays the immediate results for the whole group, which can then be discussed together. In relation to the pedagogical framework and development of the design principles, only one survey statement applied, which was: "The presented pedagogical design principles foster learning and motivation towards STEM." The statement was formulated based on the project's goals, which focus on not only learning STEM in general, but also raising interest and motivation toward these studies. Possible answer options were $4=$ strongly agree, 3 = agree, 2 = disagree, or 1 = strongly disagree. 


\section{Procedures}

\section{FG1 Sessions}

Face-to-face co-design sessions were organized in all project countries at primary, lower secondary, and upper secondary schools during the 2016-2017 school year. Participants' written consent, and in the case of minors, their parents' written consent were obtained in advance. After a short description of the STIMEY project, researchers presented the topics for discussion one by one using presentation slides. The duration of the sessions ranged from 90 to 120 minutes, which left approximately 5 to 10 minutes to discuss and write down wishes related to each topic. While open conversation enabled the elicitation of collaborative ideas between stakeholder groups, writing wishes down enabled the participants to express themselves without the pressure or anxiety of voicing their views in front of others (Duarte et al., 2015). It also gave less extroverted participants a better chance to participate. Researchers were careful not to influence the participants' ideas. The researchers clarified concepts and gave examples whenever required. Participants were told that there were no right or wrong responses. They were, however, encouraged to think about and express their wishes as representatives of their stakeholder group, instead of thinking only about their personal preferences (see also Mäkelä et al., 2017.) All sessions were recorded.

\section{FG2 Sessions}

FG2 sessions were organized during the 2017-2018 school year. In addition to face-toface sessions, some sessions were organized as video conferences to facilitate the participation of stakeholders from different locations. Participants provided written consent prior to the sessions, and all sessions were recorded. In all participating countries, the researchers conducting FG2 sessions started each session by briefly displaying the themes identified in FG1. This served as an introduction to new participants and a reminder for participants who had previously participated in FG1 sessions. Researchers then presented an overview of the FG1 results theme by theme in the form of tables. For primary school students, language was kept easy to understand. Sessions lasted between 1 and 2 hours. After presenting the results of a specific theme, the participants were asked to answer the questions related to it on the Kahoot survey. The same procedure was repeated until all themes had been displayed and the survey questions answered. The participants also had the opportunity to express themselves orally, but especially in the 1-hour sessions, the duration of conversations was limited due to time constraints.

\section{Data Analysis}

For the purposes of this study, the analysis of the data focused on participants' wishes on a general level in order to formulate the pedagogical framework and design principles. Comparisons between countries or stakeholder groups are left out of this analysis, but these can be considered in the future.

\section{FG1 Sessions}

The data analysis was initiated following the grounded theory approach (Strauss \& Corbin, 1998). First, the written data collected via an online survey were coded using open coding techniques, whereby the data were broken into meaningful conceptual components (see also Mäkelä et al., 2017). Researchers in each participant country analyzed the data in their local language, but the data were also translated into English to create a shared understanding between the researchers participating in the data analysis. The researchers shared their initial codes in English based on the data. They discussed how each concept could be related to a larger group of concepts or themes. Additionally, example responses in English were provided for each conceptual component. The researchers compared the components identified in each country, seeking similarities and differences between them. Finally, the codes were combined into wider thematic groups to create a final list of codes. After this, the second round of analysis was conducted based on a shared understanding of the thematic groups between all participant countries. Reliability of the final coding was assured; thus, after the local researchers had coded the data in their local language, the researcher in charge of the coding process revised the codes using the English translation. Discrepancies between researchers 
in the coding process were discussed and resolved, leading to some final revisions.

Table 3 presents some example citations from the data from all participant stakeholder groups and countries, initial codes used in the first round of data analysis, and groupings of the initial codes into wider thematic groups in the final coding process. For instance, for the final coding, it was agreed to merge initial codes "learner's active agency," "learning by constructing or creating knowledge," and "no memorization" into a wider thematic group named "active knowledge construction." Additionally, citations related to "experiments," "inquiry/problem-based learning," and "science labs" were merged under "experiments and inquiry." In some cases, one fragment of the data was coded under different thematic groups. For instance, the expression, "teaching should include experimental and experiential teaching," by a Finnish male upper secondary school teacher was coded under "Experiments and inquiry" (see Table 3) and also under "Learning through experiences" (see Table 4).

Table 3.

Example Citations, Their Initial Codes, and Final Codes Created During the Data Analysis

\begin{tabular}{|c|c|c|}
\hline Example citations & Initial codes & Final codes \\
\hline $\begin{array}{l}\text { "Pupils would have an important, active role." - a Finnish male } \\
\text { primary school director } \\
\text { "Students' active participation" - a Greek male lower secondary } \\
\text { school teacher }\end{array}$ & $\begin{array}{l}\text { Learner's active } \\
\text { agency }\end{array}$ & \multirow{3}{*}{$\begin{array}{l}\text { Active knowledge } \\
\text { construction }\end{array}$} \\
\hline $\begin{array}{l}\text { "Constructivist rather than teacher-centered learning" - a Greek } \\
\text { female lower secondary school teacher } \\
\text { "A place for constructing and interacting where students feel en- } \\
\text { gaged" - a Spanish female lower secondary school student } \\
\text { "Using building sets in maths" - a Spanish male primary school } \\
\text { student }\end{array}$ & $\begin{array}{l}\text { Learning by } \\
\text { constructing } \\
\text { or creating } \\
\text { knowledge }\end{array}$ & \\
\hline $\begin{array}{l}\text { "No memorization of tricky texts" - a Greek female lower secondary } \\
\text { school student } \\
\text { "Applying knowledge not in the form of memorization" - a Belarus- } \\
\text { sian male primary school director }\end{array}$ & $\begin{array}{l}\text { No } \\
\text { memorization }\end{array}$ & \\
\hline $\begin{array}{l}\text { "Various kinds of experiments" - a Greek mother of a lower second- } \\
\text { ary school student } \\
\text { "That we do experiments" - a German female primary school stu- } \\
\text { dent } \\
\text { "Teaching should include experimental and experiential teaching" - } \\
\text { a Finnish male upper secondary school teacher }\end{array}$ & Experiments & \multirow{3}{*}{$\begin{array}{l}\text { Experiments and } \\
\text { inquiry }\end{array}$} \\
\hline $\begin{array}{l}\text { "Solving general problems" - a German father of an upper second- } \\
\text { ary school student } \\
\text { "More exploring by yourself" - a Finnish female primary school } \\
\text { student }\end{array}$ & $\begin{array}{l}\text { Inquiry/ } \\
\text { problem-based } \\
\text { learning }\end{array}$ & \\
\hline $\begin{array}{l}\text { "Going to the laboratory" - a Finnish male lower secondary school } \\
\text { student } \\
\text { "Practical laboratory exercises" - a Spanish male upper secondary } \\
\text { school student } \\
\text { "Agreement with the laboratories at the university where it would } \\
\text { be possible to do experiments" - a Belarussian mother of an upper } \\
\text { secondary school student }\end{array}$ & Science lab & \\
\hline
\end{tabular}

While the open coding was made with no predetermined theoretical assumptions, during the final phase of the coding process, knowledge of existing learning theories and models was used to support the grouping and naming of the conceptual components into thematic groups. Example wishes for each theme were also collected to clarify what was meant by each code. The coded themes then served to name the design principles included in the pedagogical framework, which were 
grouped under four main categories: General principles, Socio-emotional aspects, Ways of teaching and learning, and Cross-curricular skills. At this phase of framework development, different themes were grouped under the category that they best suited thematically.

During the coding process, it was noticed that wishes expressed in sections (1) Teaching and learning, (2) STEM subjects, and (3) Cross-curricular skills as well as their subsections (see the Materials section) had a high degree of overlap. For this reason, a unified code list was created for all sections in the final phase of the analysis, instead of keeping a separate code list for each section. The frequency of wishes coded under one code could thus exceed the number of participants, as the same participant might mention the same wish under different FG sections. At this point, the analysis of the stakeholders' wishes related to cross-curricular skills was kept on a general level: only the frequency of wishes for fostering entrepreneurial skills, creativity, sustainability skills, professional skills, and transversal/cross-curricular skills expressed in sections 1-3 were coded and calculated.

\section{FG2 Sessions}

For the purpose of this paper, the number of each kind of response $(4=$ strongly agree, 3 = agree, 2 = disagree, or 1 = strongly disagree) related to the survey statement, "the presented pedagogical design principles foster learning and motivation toward STEM," was calculated, which served as a member check/validation for the framework and its design principles. In addition to the overall results, attention was paid to identifying possible differences between countries and stakeholder groups.

\section{Results}

\section{FG1 Sessions}

Table 4 presents the current version of the pedagogical framework and the titles of the pedagogical design principles. The design principles are based on the most frequent wishes identified in the data analysis of themes $1-3$, ordered by the main categories created during the data analysis. The category "general principles" entails pedagogical design principles formulated from the participant stakeholders' wishes, which can be applied generally in the LE design. "Socio-emotional aspects" contains design principles identified in the data as referring to aspects that enhance interest, motivation, engagement, and wellbeing. "Ways of teaching and learning" includes pedagogical models and ways of teaching and learning mentioned by FG1 participants. Finally, "cross-curricular skills" represents competencies that are considered particularly relevant for the STIMEY LE. The design principles related to cross-curricular skills (theme 3) were already predefined based on the objectives of the STIMEY project, which provided the context for this study. However, wishes related to entrepreneurial and professional skills, creativity, and sustainability were also spontaneously expressed in wishes related to teaching and learning (theme 1) and STEM subjects (theme 2).

General Principles. "Connectedness" of studies to students' present and future lives was the most frequently commented wish of all (see Table 4). Participant stakeholders wished that students could perceive learning as useful to their future lives and careers. Furthermore, participants wished that assessments would be more connected with applying knowledge in practical situations. Creating connections with the local community through experts' visits to schools was also desirable. In relation to STEM subjects, in particular, participants wished that teaching was both connected with present scientific achievements and discoveries, and that it provided tools for students to improve STEM development for the global benefit.

Among the most frequently commented aspects were wishes related to "personalization", referring, for instance, to the importance of considering each learner's personal competency level, and their differences in knowledge, skills, rhythm, and ways of learning. According to participant stakeholders' views, the needs of both students with learning difficulties and gifted students should be considered. In addition to the competency level, participants gave importance to considering personal preferences and interests, and providing more freedom of choice. Participants also frequently referred to the importance of "teaching and learning aids". Teachers were expected, for 
example, to have tools and know-how for facilitating effective learning, teaching, and assessment, and to be able to use research know-how in teaching. Teachers were also expected to be able to motivate students using attractive, pleasant, and inspiring teaching methods and LEs that capture students' attention.

Table 4.

The Pedagogical Framework and Design Principles Based on the Most Frequent Wishes Identified in the Data Analysis (Participants, $n=132$ )

\begin{tabular}{ll}
\hline \multicolumn{1}{c}{ General principles } & Ways of teaching and learning \\
\hline Connectedness $(\mathrm{f}=175)$ & Active knowledge construction $(\mathrm{f}=85)$ \\
Personalization $(\mathrm{f}=149)$ & Experiments and inquiry $(\mathrm{f}=88)$ \\
Teaching and learning aids $(\mathrm{f}=112)$ & ICT-enhanced learning $(\mathrm{f}=70)$ \\
Novelty $(\mathrm{f}=112)$ & Learning through experiences $(\mathrm{f}=63)$ \\
Versatility $(\mathrm{f}=91)$ & Participation and involvement $(\mathrm{f}=60)$ \\
Conventionality $(\mathrm{f}=33)$ & Learning outside the school $(\mathrm{f}=56)$ \\
$\quad$ Socio-emotional aspects & Games and gamification $(\mathrm{f}=49)$ \\
\hline Joy of learning $(\mathrm{f}=142)$ & Self-regulated learning $(\mathrm{f}=43)$ \\
Extrinsic motivation $(\mathrm{f}=88)$ & Collaborative methods $(\mathrm{f}=40)$ \\
Intrinsic motivation $(\mathrm{f}=53)$ & Reflective learning $(\mathrm{f}=28)$ \\
Justice and equity $(\mathrm{f}=27)$ & Multiple representations $(\mathrm{f}=24)$ \\
& Project-based learning $(\mathrm{f}=20)$ \\
\hline Entrepreneurial skills $(\mathrm{f}=110)$ & Cross-curricular skills \\
Creativity $(\mathrm{f}=98)$ & Sustainability skills $(\mathrm{f}=73)$ \\
\hline
\end{tabular}

Another theme various participant stakeholders frequently commented on was the importance of "novelty" in both tools and methods. Under this theme, suggestions were grouped related to novel, creative, and innovative methods, such as learning by moving (i.e., doing physical exercise) or combining STEM learning innovatively with other activities, such as cooking, sports, and building different artefacts. Further, comments opposing the use of traditional materials, such as paper textbooks, were grouped under this topic. In relation to novel assessment, many participants requested either fewer exams or no exams or assessments at all. In addition, some participants opposed numeric grading. The importance of "versatility" in teaching, learning, and assessment to the participants was also evident throughout the data. Participants frequently referred to the importance of versatile and various methods, tools, and LEs. They asked for assessments based on various criteria, such as knowledge, skills, interests, attitudes, and behavior, and grading based on different activities completed during the learning process, instead of only a final examination. Furthermore, versatility was frequently mentioned in relation to aspects that would increase motivation in learning in general and learning STEM subjects (see also Socio-emotional aspects). In addition, some positive comments related to "conventionality" in tools and methods were identified. Participants commented, for example, that the use of books, pencils, and paper should not be abandoned.

Socio-emotional Aspects. The importance of "the joy of learning" was evident throughout the responses (Table 4). Participant stakeholders referred to the importance of enjoyment, learner satisfaction, and having fun. Some participants also commented that assessments should not cause negative consequences; rather, assessments should encourage students and contribute to a positive climate. Other participants expressed concern about long school days, homework, and extracurricular work at the expense of students' free time, thereby affecting their joy of learning. Some comments were related to the importance of a positive social climate for learning, fostered by good peer and teacher-student relations. 
Motivation was a frequent theme commented on not only in subsections directed to this topic but throughout all sections. Many of the participants' comments could be categorized as "extrinsic motivation". On the one hand, participants referred to the importance of positive and rewarding feedback, encouragement, and rewards, and on the other hand, they desired inspiring, comfortable, and good LEs, equipment, tools, and materials. Participants also referred to the importance of supporting "intrinsic motivation" (i.e., the inner need to learn), personal interests, desires, needs, and competencies. Finally, a considerable number of participants referred to the importance of "justice and equity", or equal treatment of all students, no discrimination, and fair assessment.

Ways of Teaching and Learning. Participants frequently referred to learning as "active knowledge construction" (see Table 4). Wishes related to the importance of considering learner's active agency, active learning, and constructivism or learning by constructing or creating knowledge were grouped under this theme. The theme also entailed comments criticizing frontal teacher-centered teaching or memorization. Specifically, in relation to STEM studies, participants frequently wished for more learning through "experiments and inquiry", entailing laboratory experiments, scientific inquiry in learning, discovery learning, and problem-based learning. Some participants highlighted the importance of having science labs at schools.

Wishes related to "ICT-enhanced learning" were frequent in all FG sessions. This theme included comments related to the use of technology, such as technical aids, mobile technology, virtual glasses, electronic measuring systems, platforms, robots, and digital assessment tools. The importance of "learning through experiences" (i.e., learning based on everyday or real-life examples), experiential learning, and learning by doing was also made evident in co-design sessions. Similar importance was given to the theme labelled "participation and involvement", where suggestions related to participatory, interactive, and conversational teaching-learning interaction were gathered. Some participants also referred to dialogical forms of assessment and co-designing learning with students. In addition, "learning outside the school", such as field trips and visits to workplaces, was suggested by many participants. A theme labelled "games and gamification" was created based on frequent comments on learning games and game-like elements, including non-digital components such as the use of play, stories, and narrative.

Furthermore, "self-regulated learning" (i.e., independent, autonomous, and self-directed learning), "collaborative methods" (i.e., teamwork, group work, cooperation, etc.), and "reflective learning" (i.e., reflection, deep thinking, creative thinking, and critical thinking), were raised as important concerns. Comments referring to various digital and non-digital forms of presenting information, including visuals, multimedia, audio, simulations, and animations, were gathered under the thematic group labelled "multiple representations". Finally, a considerable number of participants mentioned a desire for "project-based learning" (i.e., learning through cross-curricular or transversal projects), phenomenon-based learning, or linking different subjects.

Cross-curricular Skills. Fostering cross-curricular skills was considered important by the participating stakeholders (Table 4). Wishes related to promoting "entrepreneurial skills" entailed entrepreneurial games, tournaments, and simulations. Furthermore, participants considered that experts' visits to schools (also coded under a general principle named "connectedness") and visiting different working environments (also coded under ways of teaching and learning named "learning outside the school") would support the development of entrepreneurial skills. Entrepreneurial skills were also connected to creative problem solving, idea creation, and innovation. Some participants proposed that students could practice these skills by founding their own companies. In relation to "creativity", many participant stakeholders wished that all school subjects incorporated creative thinking. Participants referred to the importance of creating alternative solutions (i.e., "thinking outside the box") and solving problems together with others. They mentioned the importance of learning about and with new inventions and tools, something that was also coded under a general principle named "novelty." Mentions of using novel technological tools were also coded under ways of teaching and learning and named "ICT-enhanced learning." In some responses, the need for creativity was linked to societal and labor needs. For instance, the creation of new businesses was mentioned as an important long-term objective. "Sustainability skills" was also considered a 
vital topic to integrate into all school subjects and school life as a whole. Participant stakeholders wished that sustainability was promoted and considered in practical ways through activities of daily life. Some concrete actions, such as caring for animals and plants, recycling, and collecting waste, were proposed. Fostering "professional skills" overlapped somewhat with fostering entrepreneurial skills. For instance, participants wished for cooperation with representatives from professional life. Likewise, helping students identify work internship opportunities and future professions they might be interested in were considered important by many participants.

\section{FG2 Sessions}

Table 5 presents the responses to the statement, "the presented pedagogical design principles foster learning and motivation toward STEM." Among all the participants, 94.34\% either agreed or strongly agreed with the statement, assuring the validity and usefulness of the pedagogical design principles for learning and motivation toward STEM from the participant stakeholders' perspectives. Oral comments received from participants confirmed that the design principles were seen as valuable in guiding the STEM LE design. The data did not reveal any clear differences in opinions between adult and learner participants, or between different age groups or genders. Only some male participants from Finland and Germany disagreed or strongly disagreed with this statement. Unfortunately, the disagreeing participants did not express their reasons for doing so.

Table 5.

The Percentages of Responses to the Statement, "The Presented Pedagogical Design Principles Foster Learning and Motivation Toward STEM" (Total of Participants, $n=137$ )

\begin{tabular}{lllll}
\hline $\begin{array}{l}\text { 1. The presented pedagogical design principles foster } \\
\text { learning and motivation toward STEM }\end{array}$ & $\begin{array}{l}\text { Strongly } \\
\text { agree }\end{array}$ & Agree & Disagree & $\begin{array}{l}\text { Strongly } \\
\text { disagree }\end{array}$ \\
\hline FINLAND & $22.73 \%$ & $72.73 \%$ & 0 & $4.54 \%$ \\
GERMANY & $29.42 \%$ & $41.18 \%$ & $11.76 \%$ & $17.64 \%$ \\
GREECE & $43.48 \%$ & $56.52 \%$ & 0 & 0 \\
BELARUS & $58.33 \%$ & $41.67 \%$ & 0 & 0 \\
SPAIN & $65.00 \%$ & $35.00 \%$ & 0 & 0 \\
\hline Total in all countries & $44.34 \%$ & $50.00 \%$ & $1.89 \%$ & $3.77 \%$ \\
\hline
\end{tabular}

\section{Discussion}

The current version of the pedagogical framework and design principles, which was developed based on the FG1 co-design sessions and validated in the FG2 sessions involving various stakeholders in five countries, is also strongly supported by both theoretical and empirical research literature. Of the theoretical considerations, the design principles are very much in line with Dewey's $(1907,1916)$ educational philosophy, which views learning as a learner-centered, active, experiential, and reflective pursuit. Further, they are in line with socio-cultural and socioconstructivist paradigms inspired particularly by the work of Vygotsky (1978), who viewed social environments and the mediating artefacts as essential for learning. Connections can also be found in Bronfenbrenner's (1979) ecological model, which views human development as taking place in reciprocal interactions with people, objects, and symbols, particularly through proximal processes in an individual's immediate environment.

\section{General Principles}

The first general design principle based on the empirical data collected in this study and supported by the research literature, "connectedness", draws attention to the importance of connecting LEs with real problems that are socially relevant (see Dewey, 1916), and with social and work-related activities (see Bronfenbrenner, 1979). Additionally, learning should be connected with learners' prior knowledge and experiences, and practices, and the transfer of learned knowledge or 
skills in new situations should be supported (Lee, 2003; Scardamalia et al., 2012).

In relation to "personalization", Dewey (1916) wrote about the importance of "flexible personal experiences" and the use of various methods according to each individual. Notions related to personalized learning are also in line with student-centered learning principles that draw attention to considering learners' prior knowledge and personal needs, presenting possibilities for choice (O'Neill \& McMahon, 2005), and adapting teaching to individual needs (Cornelius-White, 2007).

With respect to the design principle named "teaching and learning aids", based on the results of FG sessions, it seems that teachers need support tools for their demanding task of guiding learners. Previous studies (Kokotsaki et al., 2016) have indicated, for example, that the success of constructivist, discovery, problem-based, experiential, and inquiry-based teaching (all of which are considered relevant ways of teaching and learning in this framework) is connected to teachers' competence to effectively scaffold students' learning and provide guidance and support. Thus, there needs to be a balance between didactic instruction and in-depth inquiry methods. Furthermore, this design principle is related to "pedagogical learning principles" named "scaffolding progressive inquiry," "supporting the active role of tutors," and "providing tools for structuring and coordinating activities," which were proposed for web-based collaborative LEs (Rubens et al., 2005).

The importance of "versatility" in tools and methods has also been highlighted both in theoretical considerations (e.g., Bronfenbrenner, 1979; Dewey, 1907, 1916) and in empirical studies (e.g., Mäkelä \& Helfenstein, 2016). Based on Vygotsky's (e.g., 1978) theory of mediated learning, teachers are more commonly viewed as orchestrators of engaging and varying tasks, while learners interact with each other, the teacher, and mediating tools that connect them to the "highly supportive and stimulating learning environment" (UNESCO, 2012, p. 22).

With respect to "novelty", Dewey (1916) wrote, "Diversity of stimulation means novelty, and novelty means challenge to thought." The importance of novelty in tools (including but not limited to the use of ICT), methods, and spaces is also supported by recent studies (Mäkelä \& Helfenstein, 2016). However, "conventionality" in methods, tools, and spaces can be supported by prior LE models that give importance to not only LEs' responsiveness to change but also their maintenance and stability (e.g., Fraser, 1998). Learners seem to, for instance, value combining the use of technology with the use of books and other traditional tools (Mäkelä \& Helfenstein, 2016).

\section{Socio-emotional Aspects}

The importance of "thejoy of learning" expressed in FG sessions can be supported by literature highlighting the need for satisfaction, joy, and happiness at school (UNESCO, 2012). Satisfaction and positive motivation have also been found to correlate with student-centered learning (CorneliusWhite, 2007). Positive emotions, enjoyment, and interest toward learning, consisting of pleasant feelings and valuing learning, are also more likely to lead to autonomous motivational profiles such as intrinsic motivation (Loukomies et al., 2013).

According to the self-determination theory of motivation and its sub-theory named organismic integration theory (Deci \& Ryan, 2002; Ryan \& Deci, 2000), motivation orientations form a continuum. "Intrinsic motivation" is characterized by intrinsic regulation, autonomy, and selfdetermined behavior motivated by internal factors (see Ryan \& Deci, 2000). Supporting intrinsic, autonomous motivation by creating LEs that provide learners with opportunities to fulfill their basic psychological needs may increase students' motivation toward science and science-related careers (Loukomies et al., 2013; Mäkelä et al., 2017). Intrinsically motivated people are also more likely to be satisfied by and enjoy schoolwork (MacLaren et al., 2017), thus contributing to the joy of learning.

In relation to "extrinsic motivation", students with the most extreme non-regulatory style, "amotivation," may fail to perceive the activity's value to be motivated to engage in it (Deci \& Ryan, 2002; Ryan \& Deci, 2000). External regulation may lead to performing the activity to receive the expected reward or to avoid punishment. Closer to intrinsic motivation are "identified regulation" (perceived personal importance, although not necessarily part of personal beliefs and values) and "integrated regulation" (perceived personal importance, which forms part of personal beliefs and 
values). Vainikainen et al. (2015) emphasized the role of situational interest, because interest is never entirely either intrinsically or extrinsically motivated, but it varies depending on the phase of interest development and the situation itself. They also underlined the distinction between individual and situational interest, as situational interest is largely dependent on the environment, for example, the ways in which the learning situation is organized (Vainikainen et al., 2015). Attention should be paid to inspiring and motivating environments that increase well-internalized forms of extrinsic motivation and may lead to the development of intrinsic motivation (Thuneberg et al., 2018). However, creative pedagogies and informal LEs are often faced with the challenge of enhancing situational motivation to support its transformation into intrinsic motivation and a deep-learning strategy (Thuneberg et al., 2017).

Finally, socio-emotional wellbeing may be fostered by following the principles of "justice and equity", inclusiveness, equality, and accessibility, which are also supported by the literature (UNESCO, 2012).

\section{Ways of Teaching and Learning}

In relation to the design principle named "collaborative methods", Dewey $(1907,1916)$ emphasized the importance of cooperation and joint activities. Interacting with people in one's environment and cooperating with peers is also central in Vygotsky's theories (1978). Further, Bronfenbrenner (1979) wrote about the importance of joint activities and participation. The importance of collaborative methods or teamwork has also been highlighted in various contemporary studies (see, e.g., Herrington \& Oliver, 2000; Lowyck \& Pöysä, 2001; Scardamalia et al., 2012). In digital environments, collaborative methods can be fostered by technologies that enable collaboration and sharing. Using discussion communities and peer tutoring has also been found to support studentcentered learning (Cornelius-White, 2007). Further, the importance of LEs that foster "participation and involvement" is highlighted in constructivist and socio-constructivist theories, as well as in student-centered pedagogical principles (O'Neill \& McMahon, 2005). Student-centered learning has also been found to correlate with participation (Cornelius-White, 2007).

"ICT-enhanced learning" and the use of technology can be considered a natural part of twenty-first century LEs (Mäkelä \& Helfenstein, 2016). Vygotsky's (e.g., 1978) considerations of how "tools and technologies change the nature of tasks and the cognitive skills that are required to perform them" have been seen as especially valid in twenty-first century technology-enhanced LEs (Scardamalia et al., 2012, p. 25). Based on previous studies (Tseng et al., 2013), integrating technology studies and learning with technology into science and mathematics may be an effective way of raising young people's interest in STEM. The use of ICT in teaching and learning may support fostering novelty in tools and methods, which was also desired by the participants of this study.

The results of the FG discussions indicated that participants' wishes were generally in line with constructivist and socio-constructivist theories that view learning as student-centered "active knowledge construction" (O'Neill \& McMahon, 2005; see also Herrington \& Oliver, 2000; Rubens et al., 2005). FG session participants also wished for "learning through experiences". This design principle is connected to student-centered approaches such as experiential learning $\left(\mathrm{O}^{\prime} \mathrm{Neill}\right.$ \& McMahon, 2005). Learning through "experiments and inquiry", also desired by the participants in our study, can be seen as connected to student-centered approaches such as inquiry-based learning and problem-based learning (Hakkarainen \& Sintonen, 2002; O'Neill \& McMahon, 2005). In addition to physical laboratories, virtual laboratories can be employed for conducting experiments (Binkley et al., 2012).

The importance of "self-regulated learning" (Vygotsky, 1978) or learner's self-direction (Bronfenbrenner, 1979; Dewey, 1907; Scardamalia et al., 2012) is commonly present in research (Mäkelä \& Helfenstein, 2016). Notions related to self-regulated learning are in line with studentcentered learning principles that encompass responsibility, autonomy, and possibilities for choice (O'Neill \& McMahon, 2005). Metacognitive skills such as learning to learn also require self-regulation (Binkley et al., 2012).

In FG sessions, "reflective learning" (i.e., reflection and deep thinking) was raised as an 
important concern. In the present analysis, wishes related to different ways of thinking, such as "critical thinking" and "creative thinking," were also coded under this theme, while at the same time acknowledging that they can also be considered cross-curricular skills. Creative thinking, in particular, was also coded under creativity. Reflection and awareness of one's own learning was already considered fundamental by Dewey $(1907,1916)$. It has been connected, for example, with problem recognition, critical thinking, and evaluation (Soodmand Afshar \& Masoud Rahimi, 2016). Further, notions related to reflective learning are in line with student-centered learning principles that encourage a reflective approach, deep learning, and understanding ( $\mathrm{O}^{\prime}$ Neill \& McMahon, 2005). Some aspects related to student-centered learning associated with positive learning outcomes are higher-order, critical, and creative thinking (Cornelius-White, 2007).

In FG discussions, participants also emphasized the use of "multiple representations". These may include auditory, visual, textual, and pictorial representations, including sound, video, simulations, animations, pictures, text, equations, diagrams, graphs, and tables (Ainsworth, 2006). Although previous studies have shown the benefits of multiple representations in supporting learning, it is vital to support learners in understanding, interpreting, and relating to different representations, as well as to consider learners' individual and age-dependent differences when using them (Ainsworth, 2006).

In relation to the design principle named "games and gamification", previous studies have indicated that games and game-like elements can be efficient, for instance, in increasing motivation and practicing problem-solving strategies (Gee, 2007). In this study, participant stakeholders also wished that there were games, tournaments, and simulations to promote entrepreneurial skills. Further, in line with participants' wishes for "learning outside the school", Scardamalia et al. (2012, p. 14) wrote about "finding productive connections between in- and out-of-school learning environments." This design principle is very much related to the connectedness of learning with present and future life. While the design principle named "connectedness" refers to relating learning with personal significance, meaningfulness, relevance, usefulness, or applicability, "learning outside the school" refers to connecting school learning with informal (e.g., hobbies) or non-formal (e.g., science center, museum) LEs (see also Eshach, 2007).

"Project-based learning" is a constructivist form of instruction, which shares some similarities with problem-based learning and experiential learning. It is characterized by elements such as students' autonomy and active involvement, collaboration, context-dependency, and reflection within real-world practices (Kokotsaki et al., 2016; Tseng et al., 2013). In the literature review of projectbased learning (Kokotsaki et al., 2016), some positive results identified were high levels of student engagement due to the cognitive challenges and affective factors, improved self-regulated learning, intrinsic motivation, creative and deep thinking, and the understanding of scientific content. This approach has also been found to increase the effectiveness of studies, generate meaningful learning, influence future career pursuits, and make students feel that STEM is important to society's health and life (Tseng et al., 2013). Therefore, project-based learning can be seen as supportive of other design principles of this pedagogical framework, such as self-regulated learning, reflective learning, intrinsic motivation, creativity, and professional life. Notably, the use of modern digital technology (see the principle ICT-enhanced learning) is viewed as one facilitating factor in implementing projectbased learning (Kokotsaki et al., 2016).

\section{Cross-curricular Skills}

The study confirmed that the participant stakeholders viewed the design principles related to the development of cross-curricular skills named "entrepreneurial skills", "creativity", "sustainability skills", and "professional skills" as important. The importance of these highly interrelated skills is also strongly supported by the literature.

In this study, the participants connected "entrepreneurial skills" mainly with creating businesses and self-employment opportunities. In the literature, however, entrepreneurial skills are often defined in a broad sense, covering also the detection of non-profit opportunities (EdwardsSchachter et al., 2015). Also in Key Competences for Lifelong Learning proposed by the European 
Commission (2018, pp. 58), entrepreneurial competence is understood in a wide sense as turning ideas into action and creating value, including social, commercial, and cultural processes and outcomes, as well as making "a positive contribution to individuals' lives and to the sustainable development of society as a whole." Furthermore, making informed decisions, being clear about the risks, coping with uncertainty, being perseverant, and having a sense of initiative and agency are seen to contribute to this competence.

The participants in this study also connected entrepreneurial skills with "creativity". This is in line with the literature that interrelates creativity and innovation with entrepreneurship and professional competences (Binkley et al., 2012; Edwards-Schachter et al., 2015). As described by Edwards-Schachter et al. (2015), fostering technological (inventions), economic (entrepreneurship), and artistic/cultural creativity in learning requires supporting learners' ability to generate ideas, experiment, and solve problems in novel ways. Fostering innovation, in turn, implies guiding the implementation of creative ideas to create economic or social value (Edwards-Schachter et al., 2015). Similarly, in the Framework for Key Competences for Lifelong Learning (European Commission, 2018), the development of creative and innovative ideas, approaches, or artefacts is seen to contribute to employability and entrepreneurship. The framework refers to specific skills (e.g., critical thinking) and attitudes (e.g., curiosity) that comprise creativity. It also connects STEM learning and digital competences with creativity. In this framework, creativity is presented as an integrated aspect, which underpins all the eight key competences.

In relation to the design principle named "sustainability skills", participants' wishes were very much in line with the literature on sustainability education referring to the importance of adopting different values, attitudes, habits, and behaviors related to environmental, social, and economic sustainability (Frisk \& Larson, 2011). Sustainability education has also been connected to interdisciplinary approaches (see "project-based learning") and competences such as active engagement, cooperative group learning (see "collaborative methods"), connection with communities (see "connectedness"), and stakeholder perspectives (Frisk \& Larson, 2011), which are all related to many other wishes collected from the participant stakeholders. As an example of how to foster sustainability, the education for sustainable development (ESD) framework involves its own set of transversal competencies related, for example, to individual and collective responsibility intertwined with genuine ESD competencies, such as fostering a sense of belonging to the environment, as well as special competencies in science education, such as "analyzing the impact of human activities on the environment and suggesting improvement actions" (Cebrián \& Junyent, 2015). In Key Competences for Lifelong Learning (European Commission, 2018), sustainability is seen as an underlying concept connected with skills such as civic competences and entrepreneurship, participatory and collaborative skills, critical reflection, initiative taking and problem solving, as well as with STEM education.

Finally, "professional skills", also considered important by the participant stakeholders, can be seen as related to knowledge, skills, attitudes, values, and ethics needed for managing life and career as defined in the twenty-first century skills framework (Binkley et al., 2012). They include a need for being flexible and adapting to change, self-directedness and independent work (see the principle "self-regulated learning"), managing projects, goals, and time, working effectively with others in diverse teams (see "collaborative methods"), guiding and leading others, being responsible to others, and producing results. Based on the principles of situated learning (Herrington \& Oliver, 2000), both professional and entrepreneurial skills can be fostered by providing authentic contexts that reflect the ways knowledge will be used in real-life, providing insights into expert performance and the modelling process, as well as promoting articulation to enable tacit knowledge to be made explicit, as is typical for situated learning.

\section{Conclusions}

The design principles selected for the current version of the pedagogical framework based on various stakeholders' views and supported by the theoretical and empirical literature are 
considered in the STIMEY LE design. In addition, some design principles, such as the importance of a sense of belonging, or considering local and global educational needs and challenges, did not emerge in the data analysis, but are considered relevant in the STIMEY LE design based on previous studies (Mäkelä, 2015; Mäkelä \& Helfenstein, 2016). In the final phase of this study, the developed framework will be reviewed in FG3 sessions by experts in STEM, local curricula, educational policy, and educational technology. Additionally, the literature review will be extended to support the final framework version. This may still lead to some changes and improvements. However, the feedback received in FG2 as well as the support found in the literature already initially confirm both the practical usefulness and theoretical validity of this framework version in LE design, whereas final practical usefulness can then be proven after the framework has been applied in the STEM LE design.

Both the results of this study and previous literature suggest that many teaching and learning principles are highly interrelated. For instance, novel tools and methods, "collaborative methods", reflective learning, and entrepreneurial skills may support creativity and innovation, and vice versa. Instead of focusing on singular design principles, it is therefore recommended that LE designs take into account a wide range of design principles based on the assessment of stakeholders' wishes and the research literature. While this study has focused on analyzing the participants' wishes on a general level in order to formulate the pedagogical framework and design principles for the STIMEY LE, it should be noted that in the future, it would also be useful to compare differences between countries, stakeholder groups, genders, and age groups (primary, lower and upper secondary school students), as well as consider individual contributions that clearly differ from shared views. In this way, it would be possible to see how differing, critical, or minority views could be taken into account in both the LE design and use.

\section{Acknowledgment}

This project has received funding from the European Union's Horizon 2020 research and innovation program, Science Technology Innovation Mathematics Engineering for the Young 20162019, under grant agreement No 709515. Any opinions, findings, and conclusions or recommendations expressed in this material reflect only the authors' views, and the Union is not liable for any use that may be made of the information contained therein. We are especially grateful to the stakeholders participating in the focus group sessions in the project countries as well as to various researchers of this project who have contributed to the data gathering and analysis.

\section{References}

Ainsworth, S. (2006). DeFT: A conceptual framework for considering learning with multiple representations. Learning and Instruction, 16(3), 183-198. doi: 10.1016/j.learninstruc.2006.03.001

Amadio, M. (2013). A rapid assessment of curricula for general education focusing on cross-curricular themes and generic competences or skills. Paper commissioned for the EFA Global Monitoring Report 2013/4, Teaching and learning: Achieving quality for all. https://www.icet4u.org/docs/225939e.pdf

Binkley, M., Erstad, O., Herman, J., Raizen, S., Ripley, M., Miller-Ricci, M., \& Rumble, M. (2012). Defining twenty-first century skills. In: P. Griffin, B. McGaw \& E. Care (Eds.), Assessment and teaching of 21st century skills (pp. 17-66). Springer. http://dx.doi.org/10.1007/978-94-007-2324-5_2

Bronfenbrenner, U. (1979). The ecology of human development: Experiments by nature and design. Harvard University Press.

Cebrián, G., \& Junyent, M. (2015). Competencies in education for sustainable development: Exploring the student teachers' views. Sustainability, 7(3), 2768-2786. https://doi.org/10.3390/su7032768

Cornelius-White, J. D. (2007). Learner-centered teacher-student relationships are effective: A meta-analysis. Review of Educational Research, 77(1), 113-143. doi: 10.3102/003465430298563

Deci, E. L., \& Ryan, R. M. (2002). Overview of self-determination theory: An organismic dialectical perspective. In E. Deci \& R. M. Ryan (Eds.), Handbook of self-determination research (pp. 3-33). University of Rochester Press.

Dewey, J. (1907). The school and society. University of Chicago Press. 
Dewey, J. (1916). Democracy and education: An introduction to the philosophy of education. Electronic version by the University of Virginia American Studies Program 2003. http://xroads.virginia.edu/ hyper2/Dewey/TOC. html

Duarte, A., Veloso, L., Marques, J., \& Sebastião, J. (2015). Site-specific focus groups: Analysing learning spaces in situ. International Journal of Social Research Methodology, 18(4), 381-398. https://doi.org/10.1080/13645579 .2014 .910743

Edwards-Schachter, M., García-Granero, A., Sánchez-Barrioluengo, M., Quesada-Pineda, H., \& Amara, N. (2015). Disentangling competences: Interrelationships on creativity, innovation and entrepreneurship. Thinking Skills and Creativity, 16, 27-39. doi: 10.1016/j.tsc.2014.11.006

Eshach, H. (2007). Bridging in-school and out-of-school learning: Formal, non-formal, and informal education. Journal of Science Education and Technology, 16(2), 171-190. doi: 10.1007/s10956-006-9027-1

European Commission (2018). Proposal for a council recommendation on key competences for lifelong learning. https:// eur-lex.europa.eu/legal-content/EN/TXT/PDF/?uri=CELEX:52018SC0014\&from=EN

European Union (2016, April). STEM skills for a future-proof Europe: Fostering innovation, growth and jobs by bridging the EU STEM skills mismatch. EU Stem Coalition.

Fraser, B. J. (1998). Classroom environment instruments: Development, validity and applications. Learning Environments Research, 1, 7-33. https://doi.org/10.1023/A:1009932514731

Frisk, E., \& Larson, K. L. (2011). Educating for sustainability: Competencies \& practices for transformative action. Journal of Sustainability Education, 2, 1-20.

Gee, J. P. (2007). What video games have to teach us about learning and literacy (2nd ed.). Palgrave Macmillan.

Hakkarainen, K., \& Sintonen, M. (2002). The interrogative model of inquiry and computer-supported collaborative learning. Science \& Education, 11(1), 25-43.

Herrington, J., \& Oliver, R. (2000). An instructional design framework for authentic learning environments. Educational Technology Research and Development, 48(3), 23-48. https://doi.org/10.1007/BF02319856

Jenkins, H. (2006). Convergence culture: Where old and new media collide. New York University Press.

Jiménez Iglesias, M., Nistor, À., Gras-Velázquez, G., Balta, M., Caeiro Rodríguez, M., Caine, O.... \& Valero, A. (2016). Multi-stakeholder partnerships in STEM education. Scientix Observatory Series.

Koelsch, L. E. (2013). Reconceptualizing the member check interview. International Journal of Qualitative Methods, 168-179. https://doi.org/10.1177\%2F160940691301200105

Kokotsaki, D., Menzies, V., \& Wiggins, A. (2016). Project-based learning: A review of the literature. Improving Schools, 19(3), 267-277.

Könings, K. D., Seidel, T., Jeroen, J., \& van Merriënboer, G. (2014). Participatory design of learning environments: Integrating perspectives of students, teachers, and designers. Instructional Science, 42(1), 1-9.

Lee, C.D. (2003). Toward a framework for culturally responsive design in multimedia computer environments: Cultural modelling as a case. Mind, Culture, and Activity, 10(1), 42-61. https://doi.org/10.1207/ S15327884MCA1001_05

Loukomies, A., Pnevmatikos, D., Lavonen, J., Kariotoglou, P., Juuti, K., \& Spyrtou, A. (2013). Promoting students' interest and motivation towards science learning: The role of personal needs and motivation orientations. Journal of Research in Science Education, 43(5), 2517-2539.

Lowyck J., \& Pöysä, J. (2001). Design of collaborative learning environments. Computers in Human Behavior, 17(5), 507-516. doi:10.1016/S0747-5632(01)00017-6

MacLaren, R., Tran, V. H., \& Chiappe, D. (2017). Effects of motivation orientation on schoolwork enjoyment and achievement and study habits. Thinking Skills and Creativity, 24, 199-227. http://dx.doi.org/doi:10.1016/j. tsc.2017.03.003

Mäkelä, T. (2015). Developing an evaluation framework for identifying globally shared and locally specific requirements for the design and use of educational technology. Proceedings of Society for Information Technology \& Teacher Education International Conference 2015, Las Vegas, NV, United States. Association for the Advancement of Computing in Education (AACE; pp. 1220-1226). http://www.editlib.org/p/150162/

Mäkelä, T., \& Helfenstein, S. (2016). Developing a conceptual framework for participatory design of psychosocial and physical learning environments. Learning Environments Research, 19(3), 411-440. http:// doi.org/10.1007/s10984-016-9214-9 
Mäkelä, T., Pnevmatikos, D., Immonen, H., Fachantidis, N., Kankaanranta, M., \& Christodoulou, P. (2017). Considering various stakeholders' views in the design of a hybrid stem learning environment: Perceptions from Finland and Greece. In L. G. Chova, A. L. Martínez, \& I. C. Torres (Eds.), EDULEARN17 Proceedings. 9th international conference on education and new learning technologies (pp. 5517-5526).

O'Neill, G., \& McMahon, T. (2005). Student-centred learning: What does it mean for students and lecturers? In G. O'Neill, G. Moore, \& B. McMullin (Eds.), Emerging issues in the practice of university learning and teaching. AISHE.

Rubens, W., Emans, B., Leinonen, T., Gomez Skarmeta, A., \& Simons, R. -J. (2005). Design of web-based collaborative learning environments. Translating the pedagogical learning principles to human computer interface. Computers $\mathcal{E}$ Education, 47, 276-294.

Ryan, R. M., \& Deci, E. L. (2000). Self-determination theory and the facilitation of intrinsic motivation, social development, and well-being. American Psychologist, 55(1), 68-78.

Scardamalia, M., Bransford, J., Kozma, B., \& Quellmalz, E. E. (2012). New assessment and environments for knowledge building. In P. Griffin, B. McGaw, \& E. Care (Eds.), Assessment and teaching of 21st century skills. Springer.

Soodmand Afshar, H., \& Masoud Rahimi, M. (2016). Reflective thinking, emotional intelligence, and speaking ability of EFL learners: Is there a relation? Thinking Skills and Creativity, 19, 97-111.

Strauss, A., \& Corbin, J. (1998). Basics of qualitative research - Techniques and procedures for developing grounded theory (2nd ed.). Sage Publications.

Thomas, D., \& Brown, J. S. (2011). A new culture of learning: Cultivating the imagination for a world of constant change. CreateSpace.

Thuneberg, H. M., Salmi, H. S., \& Bogner, F. X. (2018). How creativity, autonomy and visual reasoning contribute to cognitive learning in a STEAM hands-on inquiry-based math module. Thinking Skills and Creativity, 29, 153-160. https://doi.org/10.1016/j.tsc.2018.07.003

Thuneberg, H., Salmi, H., \& Fenyvesi, K. (2017). Hands-on math and art exhibition promoting science attitudes and educational plans. https://www.hindawi.com/journals/edri/2017/9132791/

Tseng, K. H., Chang, C. C., Lou, S. -J., \& Chen, W. P. (2013). Attitudes towards science, technology, engineering and mathematics (STEM) in a project-based learning (PjBL) environment. International Journal of Technology Education, 23(1), 87-102. https://doi.org/10.1007/s10798-011-9160-x

UNESCO (2012). A place to learn: Lessons from research on learning environments. Technical paper No. 9. Montreal: United Nations Educational, Scientific and Cultural Organization, Institute for Statistics.

Vainikainen, M. P., Salmi, H., \& Thuneberg, H. (2015). Situational interest and learning in a science center mathematics exhibition. Journal of Research in STEM Education, 1(1), 15-29.

Vygotsky, L. S. (1978). Mind in society. The development of higher psychological processes. (M. Cole, Ed.). Harvard University Press.

Wright, N., \& Davis, R. (2014). Educating the creative citizen: Design education programs in the knowledge economy. Techne Series: Research in Sloyd Education and Craft Science A, 21, 42-61. 